\title{
Gamification of E-Participation: A Literature Review
}

\author{
Lobna Hassan \\ Gamification Group \\ Tampere University \& \\ Hanken School of Economics \\ lobna.hassan@uta.fi
}

\author{
Juho Hamari \\ Gamification Group \\ Tampere University \& \\ University of Turku \\ juho.hamari@tut.fi
}

\begin{abstract}
Gamification is one of the most commonly employed approaches for motivating individuals to participate in several types of activities. One of its largest application areas has been e-participation (i.e. citizen engagement in policy-making). Even though the required ICT infrastructure to facilitate e-participation mostly exists today, the focus of the problem has shifted towards humans; citizens are not motivated enough to participate. Gamification is a potential approach to increase motivation towards eparticipation. However, currently there is a dearth in our understanding of how gamification is being applied and researched as well as what kinds of result there exist from gamification. The aim of this paper is to synthesize research and findings on gamified eparticipation, providing directions for future research in this area.
\end{abstract}

\section{Introduction}

Citizen participation is a practice that expresses the human endeavor to influence the governance of communities [15]. With the rapid development of technologies such as the Internet and smartphones, avenues for citizen participation have expanded to the digital realm under the umbrella of "e-participation": citizen participation through information and communication technologies $[40,60]$. Nonetheless. citizens remain relatively inactive, or at least insignificantly engaged in offline or online participation, oblivious to the societal importance of such practice [3,11, 14, 16, 21]. E-participation is a difficult area of human engagement as it can be seen to exists outside the common hurdles of the everyday mundane life and where the effects of participation are often invisible or take time to materialized. Eparticipation tools however can be designed to encourage citizen engagement through hedonic design strategies such as through gamification [32, 45, 65].
Gamification refers to designing systems, services and processes to provide positive, engaging experiences similar to the ones games provide [32]. During the last years, we observed an increased interest in gamifying information systems with the intent to positively impact user engagement, often when the subject of engagement exists outside the common hurdles of the everyday, mundane life $[27,37,44,50$, $51,65,84]$. In the field of e-participation: gamification has the potential to increase citizen participation, possibly leading to better governmental decisionmaking, legitimacy and increased trust in government $[1,7,19,21,29,38]$. Hence, a plethora of research and practical work is being carried out to gamify eparticipation. The aim of this paper is to synthesize the research that has been carried out in the area of gamified e-participation so as to develop a comprehensive understanding of gamified eparticipation and highlight avenues for future research. This study followed a literature review process focused on the summarization of knowledge [58]. Specifically, we conducted a representative, broad, descriptive review [85]. This study allows a vantage point on what research on gamified e-participation has been conducted, the findings it offers as well as avenues for future research.

\section{Background}

Despite participation being a relatively mature field of research, it remains problematic to conclusively define participation $[6,15]$ or hence e-participation. Eparticipation has been defined in terms of citizen engagement with each other and with their government toward the betterment of their community [33]. The betterment of a community is, however, an elusive idea, difficult to define or measure. E-participation has also been defined in terms of citizen involvement in political processes [10]. Of these processes, perhaps most specifically and seminally, e-participation has been understood in Ann Macintosh's terms in light of citizens' participation in the policy-making process [40]. Policy-making is naturally an integral aspect of 
governance that encompasses several stages 1) agenda setting, in which objectives of policies are determined, 2) analysis, where the objectives of and needs for policies are analyzed, 3) creation, which involves the drafting and passing of policies, 4) implementation, which is about the enactment of passed policies, and 5) monitoring which is about the continuous observation of implemented policies, and society so as to detect shortcomings and trigger future cycles of policymaking. Three levels of citizen engagement with these stages of policy making could be possible [40]; 1) enabling; a basic level, focused on provision of information to citizens, 2) engaging; an intermediate level, in which limited two-way citizen-government interaction is encouraged, and 3) empowering; where citizens actively co-create with their governments.

Gamification of e-participation is often categorized as a unique and effective approach to engage citizens in e-participation and policy-making [52]. Gamification is commonly understood as the introduction of game elements to serious, mundane, non-gaming contexts (such as the context of eparticipation) to induce motivation and engagement [19]. Gamification is about the design of systems, services and processes towards inducing engaging, positive psychological experiences such as enjoyment or gamefulness [32]. Such experiences then can translate into behavioral engagement with the context of gamification [27]. Gamification has hence been employed to induce engagement in the contexts of for example crowdsourcing [44], production management [84] as well as education and health management amongst other contexts [27, 37]. Some of the most commonly utilized elements of gamification in these contexts have been: points, badges and leaderboards amongst others $[27,37,44,50,51,65,84]$. Gamification of e-participation, in particular has been observed to induce increased citizen engagement with the government as is intended from its introduction to e-participation $[8,9,11,18,20,22,31,34,35,38]$. Gamified e-participation is, however, often misunderstood in practice, implicating its potential for success [4, 28]. It is hence of importance to understand how this unique approach to fostering e-participation has been implemented and the actual and potential outcomes that it can bring about.

\section{Methodology}

Literature review approaches can be divided into four distinct approaches depending on the goal of the review: 1) summarization of knowledge, 2) data aggregation (of empirical studies), 3) explanation building or 4) critical assessment of extant literature [58]. Whereas the first type of reviews (including narrative, descriptive or scoping reviews) attempts to broadly map and describe a body of literature, data aggregation approaches attempt to aggregate results in a field and specially between specific sets of variables. The explanation building approach attempts to build theory without meticulously describing the field it reports on and the critical assessment approach attempts to primarily poke holes in existent literature. Given the goal of this review, we adopt a summarization of knowledge approach. More specifically, we aimed to conduct a representative, broad and descriptive review employing a systematic literature search and coding.

We follow a combination of author and concept centric coding strategies as guided by [85] in order to organize existent literature per publication and per concepts presented in them to describe the body of literature quantitatively. Therefore, the process employed by this study proceeded as follows: 1) explorative literature search to map relevant keywords, 2) systematic literature search (of Scopus database), 3) inclusion and exclusion procedures, 4) backward search, 5) forward search, 6) concept-centric coding and analysis of literature, 7) author-centric coding of literature, 8) findings reporting (in this study).

As Ann Macintosh's framework to characterizing e-participation [40] is one of the esteemed frameworks to defining and examining e-participation, we adopted it in examining and coding the concepts emergent in the literature review. Hence, the aspects collected from the literature as guided by the research problem and theory included: Reference, e-participation study focus, type of manuscript (conference paper/ journal article / book chapter, etc.), type of study (empirical / nonempirical), research methods, gamification evaluation approach (qualitative / quantitative / mixed), eparticipation level focus of manuscript (enabling / engaging / empowering), policy-making stage focus of manuscript (all/ / agenda setting / analysis / creation / implementation / monitoring), gamification elements employed if a tool is reported on, results from gamification (positive / negative / neutral/ mix / not reported), psychological and behavioral outcomes of gamification and whether a governmental unit was involved in the research.

The literature search was carried out in May 2018. The database of Scopus was queried using the following search string: (TITLE-ABS-KEY ( gamif*) AND TITLE-ABS-KEY ( gov*) OR TITLE-ABSKEY ( poli* ) OR TITLE-ABS-KEY ( urban ) OR TITLE-ABS-KEY ( eparticip* ) OR TITLE-ABSKEY ( e-particip*) ) AND ( LIMIT-TO ( DOCTYPE , "cp" ) OR LIMIT-TO ( DOCTYPE, "ar" ) OR LIMIT-TO ( DOCTYPE, "ch" ) OR LIMIT-TO ( DOCTYPE, "ip" ))". 
The keyword gamif* includes all forms of the word gamification. Keywords gov*, poli*, urban, eparticip*, e-particip* where used to include literature related to eparticipation. We limited the search to journal articles, conference papers, book chapters thus automatically excluding for example conference track introductions. Before deciding on the keywords, exploratory searches of the literature were made to ensure that the keywords used in the literature search covered the relevant literature.

Figure 1 depicts the literature search process which started with the identification of 216 manuscripts, from which 4 were excluded as they were in languages other than English. 2 duplicates were next removed. An additional 5 manuscripts $[49,56,59,66,82]$ were excluded as they were inaccessible through the libraries of the authors of this paper or through contacting the authors of the papers in question through ResearchGate. Next, papers on topics other than gamified e-participation in policy making were excluded, leaving 50 manuscripts. Following the backwards references of these manuscripts revealed 4 relevant manuscripts $[7,17,64,71]$. Forward references revealed 2 more [54, 70]. In total 56 manuscripts were included in this literature study. Categorization and coding of these manuscripts as seen in Tables 1-3 was done according to what is reported in the reviewed manuscripts. For example: papers indicating that they aim to enable/engage/empower citizens were categorized as such in respective categories. Otherwise, the manuscript would be categorized in a "generic" category.

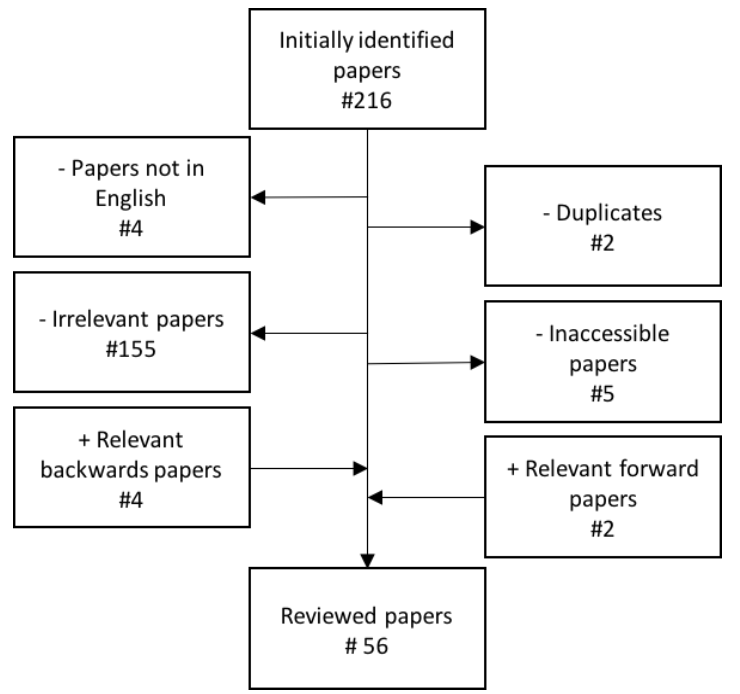

Figure 1. Literature search process and outcomes

\section{Findings and Discussion}

Thirty-three of the identified manuscripts reported on empirical research while twenty-three reported on non-empirical research. Most manuscripts reported on research that employed more than one research method (see Table 1). Design, prototyping, and evaluation of gamified e-participation tools and related methods are the most popular. The field of gamified e-participation appears highly geared towards obtaining primary insights which is of significant importance in any research field specially an emerging one. Additionally, the observed utilization of mixed methods highlights an attempt towards obtaining findings from various vantage points that can possibly complement each other, however, it may also indicate a lack of maturity in the field as it can show a lack of confirmatory studies based on established theoretical considerations

In terms of e-participation focus, it appears (see Table 2) that civic engagement is the most researched focus area. Civic engagement is not only a hard to concretely define concept [64] but it is also often employed as a focus because of how generic it is. [28]. While a generic study of e-participation is presumably of relevance to most sub-domain areas of gamified eparticipation [28], generic research is likely to make contextualized implementations of gamification more challenging as researchers would need to exert additional work in contextualizing generic knowledge to their purposes.

With regards to stages of policy-making, 24 of the reviewed manuscripts generically examined gamified e-participation in all stages of policy-making (see Table 2). Focused research on certain stages of policymaking is hence encouraged as it could help ensure the smooth implementation of gamification attuned to specific areas of policy-making. The reviewed research often examined more than one stage at a time, however, no research appeared to be carried out with a specific focus on the "creation" stage of policymaking. This is possibly because policy creation remains a duty exclusive of governmental agencies [40] hence, there is a lack of motivation to research it. Research is hence encouraged to investigate the needs for the introduction of motivational and engagement tools to the creation stage of policy-making.

The implementation stage of policy-making appears the most researched, with 20 manuscripts focused on it. In this stream of research, we observe a significant focus on the creation of "good citizens" [2, $18,34,88]$. While this direction of research could be of significant societal benefit, as no one can hardly argue 
Table 1. Summary of the research methods employed by the reviewed manuscripts

\begin{tabular}{|l|l|l|l|l|l|}
\hline Research methods & Studies & $\#$ & Research methods & Studies \\
\hline Design \& Prototyping & $\begin{array}{l}{[8,9,11,13,20,22,31,34,35} \\
38,39,48,53,54,61,62,63,64, \\
70,71,72,75,76,87]\end{array}$ & $\begin{array}{l}\text { Design } \\
\text { implementation) }\end{array}$ & $\begin{array}{l}{[5,17,18,42,47,} \\
57,83,86]\end{array}$ \\
\hline $\begin{array}{l}\text { Field studies \& } \\
\text { experiments }\end{array}$ & $\begin{array}{l}{[8,9,13,20,22,34,35,39,53,} \\
61,62,64,74,75,76,77,78,87]\end{array}$ & 18 & Case studies & {$[4,48,68,69,74]$} & 5 \\
\hline $\begin{array}{l}\text { Surveys (qualitative } \\
\text { \& quantitative) }\end{array}$ & $\begin{array}{l}{[4,8,9,13,20,34,54,61,62,63,} \\
64,74,75,76,77,78]\end{array}$ & 16 & Literature reviews & {$[48,54,55,79]$} & 4 \\
\hline Theoretical analysis & $\begin{array}{l}{[2,7,12,16,17,23,24,28,36,} \\
41,52,67,73,81,86,88]\end{array}$ & 16 & $\begin{array}{l}\text { Qualitative } \\
\text { observation studies }\end{array}$ & {$[13,69,75,76]$} & 4 \\
\hline Log data analysis & $\begin{array}{l}{[8,9,11,13,22,34,35,38,53,} \\
61,62,64,69,70,72,76,78,87]\end{array}$ & Ethnography & {$[23,26,80]$} \\
\hline $\begin{array}{l}\text { User focus groups \& } \\
\text { interviews, debriefing }\end{array}$ & $713,20,31,39,48,62,63,64,68,78]$ & 11 & Expert interviews & {$[4,64]$} & 3 \\
\hline
\end{tabular}

that encouraging the use of sustainable transport is undesirable in most societies, it raises concerns in the literature on the ethics of employing gamification in e-participation and in governmental dealings in general [28, 41]. While gamification could and is often utilized to induce "good" habits, it is of danger in e-participation to utilize it to foster habits that are determined by authorities. Research in this direction should hence be cautioned.

It is often observed that actual involvement from the government in gamified e-participation research is lacking $[13,23,34,35,39,42,54,60,62,67,70$, $72,77]$. That could be due to the lack of easy channels of contact between researchers and governments. Research involving the government could additionally impose increased legal considerations that researchers would rather avoid. Government involvement is nonetheless essential by nature in this research stream and hence some researchers often simulated a governmental presence on the gamified tools they were evaluating [20, 74, 75, 76]. Nonetheless, governmental presence in research is still observed $[4,8,9,11,38,53,68,71]$. In fact, although such reports are rare, some of the research has led to actual policy implementations [69]. Such outcomes should be highlighted to increase citizens trust in governments and research.

The majority of the research (35 manuscripts) focused on engaging citizens in limited two-way citizen participation. As seen in Table 2, more than one level of e-participation were often researched at the same time. The enabling level of e-participation is the least researched, with only 7 manuscripts. This is possibly due to the enabling level of e-participation being one that is usually seen to require little engagement from the citizens, hence, it may not have been of interest to look into its gamification. Future research is especially encouraged to research the eparticipation levels of enabling and empowering.

As can be seen in Table 2: certain sub-domains of e-participation in policy-making lack research. Researcher are encouraged to investigate gamification in for example law enforcement, civic education and engagement with open governmental data so as to further conclude whether and how gamification could be of value to these domains.

With regards to the employed elements of gamification in the reviewed manuscripts as seen in Table 3, during the coding of this review, we adhered to what the authors of reviewed manuscripts report as game elements with no addition or subtractions from their reports. The most commonly employed element of gamification design is points. Naturally, points are a basic design element without which several other gamification elements would not be implementable such as leaderboards, user rankings or idea rankings.

Elements that rank users in a competition such as levels and leaderboards are the second most popular game elements employed in gamified e-participation (Table 3). Competitive gamification designs and the elements closely tied to them such as rankings, missions, and achievements are overall the most popularly employed. Competition fuels engagement and the repetitive use of a service [46] hence these findings are not unwarranted. Yet, competition also often leads to negative behavior between users such as hyper competitiveness, bullying and behavior to break the system for one's benefit [23, 76]. It is hence interesting to observe that a number of competitive implementations attempted to shift the focus of the competition from a competition between users to one between ideas [8, 9, 20, 64, 69], often employing leaderboards of ideas instead of or next to leaderboards of users. 
Table 2. Summary of e-participation specific aspects of the reviewed manuscripts

\begin{tabular}{|c|c|c|c|c|c|}
\hline Focus of studies & Studies & \# & $\begin{array}{l}\text { Policy-making } \\
\text { stage }\end{array}$ & Studies & \# \\
\hline Civic engagement & $\begin{array}{l}{[2,7,8,9,16,28,31,} \\
41,55,64,73,76,78, \\
79,80,81,83,86]\end{array}$ & 18 & All & $\begin{array}{l}{[4,7,12,16,20,22,24,28,31,36,} \\
41,48,52,54,64,68,73,74,76,77, \\
78,79,81,83]\end{array}$ & 24 \\
\hline Urban planning & $\begin{array}{l}{[4,18,20,24,36,48,} \\
53,54,74,75,77]\end{array}$ & 11 & Agenda setting & {$[8,9,53,55,69,75]$} & 6 \\
\hline Crowd sensing & $\begin{array}{l}{[5,13,17,42,47,63,} \\
69,71,72,87]\end{array}$ & 10 & Analysis & {$[8,9,53,55,69]$} & 5 \\
\hline $\begin{array}{l}\text { Urban mobility \& } \\
\text { mapping }\end{array}$ & $\begin{array}{l}{[34,35,57,61,62,67,} \\
68,70]\end{array}$ & 8 & Creation & - & 0 \\
\hline Elections & {$[23,26]$} & 2 & Implementation & $\begin{array}{l}{[2,5,11,18,23,26,34,35,38,39,} \\
42,53,57,61,67,70,72,80,86,88]\end{array}$ & 20 \\
\hline Civic learning & {$[22,52]$} & 2 & Monitoring & $\begin{array}{l}{[8,9,13,17,42,47,55,62,63,69,} \\
71,72,75,80,87]\end{array}$ & 15 \\
\hline $\begin{array}{l}\text { Welfare } \\
\text { management }\end{array}$ & {$[11,38]$} & 2 & $\begin{array}{l}\text { E-participation } \\
\text { level }\end{array}$ & Studies & \# \\
\hline Law enforcement & [39] & 1 & All & {$[4,7,16,28,36,41,53,65,79,81]$} & 10 \\
\hline Education & [88] & 1 & Enabling & {$[12,22,34,35,61,70,88]$} & 7 \\
\hline $\begin{array}{l}\text { Open government } \\
\text { data }\end{array}$ & {$[12]$} & 1 & Engaging & $\begin{array}{l}{[2,5,11,13,17,18,20,23,24,26,} \\
31,38,39,42,47,48,53,55,57,62, \\
63,67,69,71,72,73,74,75,76,77, \\
78,80,83,86,87]\end{array}$ & 35 \\
\hline & & & Empowering & {$[8,9,48,54.68,74,75,77,78,83]$} & 10 \\
\hline
\end{tabular}

Depending on their personality, users might react to idea-based competitive designs by cooperating more with each other on getting the best ideas to win the competition, fueling positive engagement, or they might still engage in negative competitive behavior amongst each other [64]. There is hence, at least a possibility for cooperative, group advancing behavior to emerge within the competition, making such ideabased competitive designs worthy of further refinement and investigation. Cooperation and team setups also appear to be researched in the identified manuscripts.

Interestingly, elements such as social features were often explicitly considered by some researchers as game elements $[8,9,17,20,42,47,57,69,75,76$, $80]$, while not considered or classified as such by others $[8,31,63,74,77,78]$ as is also reflected on by the reviewed literature [81]. Some research considered the observed popularity in satire and memes during election times as gamification of elections [26] while no other research reflected on satire and memes as elements of gamification. These observations serve to showcase a lack of agreement in the e-participation and gamification fields alike, on what is or is not gamification. It alternatively appears that defining gamification in terms of experiences of gamefulness and related positive psychological experiences outcome of gamification is an alternative route to categorize and measure gamification [32]. The majority of reviewed research does report on psychological outcomes from gamification in terms of experiences (or lack thereof) of gamefulness, motivation or enjoyment to name a few $[4,8,9,20$, $22,23,35,39,62,63,64,74,75,76,77,78,87]$. Nonetheless, research is observed to pay little attention to reporting the psychological outcomes of gamification $[31,35,48,53,61,69,70,80]$ which is problematic as positive psychological experiences from gamification are a precursor for its success in terms of inducing a behavioral change [27] such as engagement with policy-making. Most of the conducted evaluations of research involving gamification implementations are quantitative (Table 3 ). Qualitative studies could reveal nuanced differences in the reception of and outcomes from gamified e-participation and hence are encouraged.

The overwhelming majority of reviewed manuscripts point towards positive outcomes or at least mixed outcomes from introducing gamification to e-participation. These outcomes, reported in the reviewed manuscripts, included increased engagement levels with the gamified tools, positive psychological experiences from the tools in questions 
as well as some behavioral change such as increased utilization of sustainable transport.

Negative results were hardly observed and mainly pertained to low engagement levels with the gamified tools, without a negative impact on behavior outside engagement. Nonetheless, it is possible that the lack of negative results reported from gamification in eparticipation could be due to that failed or negative gamification research, in general, is rarely reported on or published [30]

Table 3. Summary of gamification specific aspects of the reviewed manuscripts

\begin{tabular}{|c|c|c|c|c|c|}
\hline $\begin{array}{l}\text { Gamification } \\
\text { elements }\end{array}$ & Studies & \# & $\begin{array}{l}\text { Gamification } \\
\text { elements }\end{array}$ & Studies & \# \\
\hline Points & $\begin{array}{l}{[8,9,11,13,17,22,23,31,34,35,} \\
38,39,42,47,53,54,57,61,62,63, \\
71,74,75,76,77,7886,87]\end{array}$ & 28 & $\begin{array}{l}\text { Social media } \\
\text { integration }\end{array}$ & {$[20,23,31,64,69]$} & 5 \\
\hline \multirow[t]{2}{*}{$\begin{array}{l}\text { User rankings, levels } \\
\& \text { leaderboards }\end{array}$} & \multirow{2}{*}{$\begin{array}{l}{[8,9,13,17,20,22,31,34,35,39} \\
42,47,57,63,70,74,75,76,77,78 \\
83,86,87]\end{array}$} & \multirow[t]{2}{*}{23} & $\begin{array}{l}\text { Stories, } \\
\text { characters }\end{array}$ & {$[20,34,54,62,80]$} & 5 \\
\hline & & & Notifications & {$[17,20,53,64]$} & 4 \\
\hline \multirow{2}{*}{$\begin{array}{l}\text { Goals, missions, to- } \\
\text { dos, quests, tasks, } \\
\text { challenges }\end{array}$} & \multirow{2}{*}{$\begin{array}{l}{[8,9,17,22,23,34,53,54,57,64,} \\
69,70,71,72,74,75,76,77,78,80, \\
86]\end{array}$} & \multirow[t]{2}{*}{21} & Feedback & {$[17,71,72]$} & 3 \\
\hline & & & Newsfeed & {$[57,64,70]$} & 3 \\
\hline $\begin{array}{l}\text { Achievements, } \\
\text { badges, medals }\end{array}$ & $\begin{array}{l}{[8,9,11,22,31,34,35,38,47,63} \\
64,76,83,86]\end{array}$ & 14 & Punishments & {$[13,31,87]$} & 3 \\
\hline User profiles & $\begin{array}{l}{[8,9,20,22,47,62,64,70,74,75,} \\
76,77,78]\end{array}$ & 13 & Player roles & {$[20,54]$} & 2 \\
\hline Competition & $\begin{array}{l}{[8,9,13,20,31,42,57,63,64,69,} \\
75,77,87]\end{array}$ & 13 & Avatars & {$[20,42]$} & 2 \\
\hline Location tagging, & $\begin{array}{l}{[20,23,24,42,47,53,57,62,64,74,} \\
75,76,78]\end{array}$ & 13 & AR & {$[20,62]$} & 2 \\
\hline Time constraints & $\begin{array}{l}{[17,57,63,64,74,75,76,77,78,86,} \\
87]\end{array}$ & 11 & Rules & {$[71,72]$} & 2 \\
\hline $\begin{array}{l}\text { Posting, sharing, } \\
\text { commenting }\end{array}$ & $\begin{array}{l}{[8,9,17,20,42,47,57,69,75,76,} \\
80]\end{array}$ & 11 & Forums & {$[23]$} & 1 \\
\hline $\begin{array}{l}\text { Rewards, prizes, } \\
\text { incentives }\end{array}$ & {$[17,23,34,35,53,62,68,70,71,72]$} & 10 & $\begin{array}{l}\text { Satire } \\
\text { memes }\end{array} \quad \&$ & [26] & 1 \\
\hline $\begin{array}{l}\text { Cooperation, teams, } \\
\text { player communities }\end{array}$ & {$[17,23,53,57,64,70,76]$} & 7 & Emoticons & {$[75]$} & 1 \\
\hline $\begin{array}{l}\text { Ideas rankings, likes } \\
\& \text { leaderboards }\end{array}$ & {$[8,9,17,20,57,64,69,75,76]$} & 9 & Downvoting & {$[17]$} & 1 \\
\hline Progress bars & {$[42,64,70,72,76,78]$} & 6 & Chat & {$[20]$} & 1 \\
\hline Reputation systems & {$[17,74,76,77,78]$} & 5 & Hardware & [39] & 1 \\
\hline $\begin{array}{l}\text { Gamification } \\
\text { Evaluation }\end{array}$ & Studies & \# & $\begin{array}{l}\text { Gamification } \\
\text { Evaluation }\end{array}$ & Studies & \# \\
\hline Non-applicable & $\begin{array}{l}{[2,4,5,7,12,16,17,18,24,28,36,} \\
41,42,47,52,55,57,67,73,79,81, \\
83,86,88]\end{array}$ & 24 & Quantitative & $\begin{array}{l}{[8,9,11,22,34,35,} \\
38,53,63,70,72,74, \\
77,87]\end{array}$ & 14 \\
\hline Mix & {$[13,20,61,62,64,75,76,78]$} & 8 & Qualitative & {$[23,31,39,68,69,80]$} & 6 \\
\hline Not described & {$[42,48,54,71]$} & 4 & & & \\
\hline Findings & Studies & \# & Findings & Studies & \# \\
\hline Positive & $\begin{array}{l}{[8,9,11,20,22,31,34,35,38,39} \\
53,62,63,64,68,69,70,71,72,74, \\
77,78,87]\end{array}$ & 23 & Mix & {$[4,23,26,75,76,80]$} & 6 \\
\hline $\begin{array}{l}\text { Secondary \& } \\
\text { theoretical studies }\end{array}$ & $\begin{array}{l}{[2,7,12,16,24,28,36,41,52,55,} \\
67,73,79,81,88]\end{array}$ & 15 & $\begin{array}{l}\text { Negative } \\
\text { Inconclusive }\end{array}$ & {$[13,61]$} & 2 \\
\hline $\begin{array}{l}\text { Not reported / not } \\
\text { conducted }\end{array}$ & {$[5,17,18,42,47,48,54,57,83,86]$} & 10 & & & \\
\hline
\end{tabular}


Effective gamification requires attentive user and context analysis $[16,28,31,45,79]$. Some of the reviewed research appeared to pay close attention to context and user analyses [11,38, 62, 64, 68], while other research seemed to fail to report on such analyses [72, 75]. The logic and process of gamification design hence remain in a relative black box, inaccessible to other researchers and practitioners in the field. We highly encourage researchers to report on their design and analysis processes, providing detailed insights into design for gamified e-participation.

Gamification can be counterproductive in certain context of e-participation if it affects equal access to vital services such as healthcare, or if it creates dimensions for discrimination between individuals in the type and quality of service they can receive $[4,7$, $28,76,78]$. The digital divide is a concept of high relevance to e-participation research and it is possible that gamification, as other e-participation means before it, could strengthen access to e-participation for certain educated segments of a population, while lowering it for other segments, leading to biases in governmental decision-making [25]. It is possible, however, that gamification could positively influence peoples' belief in their political abilities (political self-efficacy), encouraging them to participate more. We encourage researchers to maintain a holistic and critical view towards gamified e-participation. Some e-participation gains from gamification could be desired but may lead to other e-participation losses. Aspects such as equal access, political self-efficacy, and representativeness of the populace on gamified eparticipation tools should be investigated.

Furthermore, we observed that most gamified eparticipation designed and evaluated in the examined literature were researched by domain-specific researchers. Gamification design by nature is multidisciplinary [43] and in the context of eparticipation, in specific, requires knowledge of psychology, game design and political theory amongst other disciplines [28]. This observed disconnect between gamification, game design, psychology and political theory could lead to the design and introduction of gamified e-participation tools that do not meet their objective. We hence call for multidisciplinary research on gamified eparticipation.

\section{Conclusions}

Overall, as seen in the results of this literature study, increased engagement outcomes are reported from gamified e-participation in overwhelming numbers relative to the reported mixed or potentially negative outcomes from gamification. We encourage research on gamified e-participation, especially qualitative, longitudinal studies. Research involving the government or at least that simulates government involvement is of importance to instill a sense of trust in the conducted research in the research participants. Researchers are invited to attempt contextualized study of e-participation sub-domains that lack gamification research such as the domains of law enforcement and civic education. Similarly, research is encouraged in stages of policy-making that have not seen a plethora of research, such as the stages of agenda setting and policy analysis and creation. We further call on researchers to investigate various and emerging elements of gamification design. and to examine the psychological experiences - such as enjoyment and gamefulness - that gamification instills in users.

\section{Acknowledgments}

This work was supported by the Finnish foundation for economic education (10-5562 and 126385), Business Finland (5479/31/2017 and 40009/16) and project partners, Satakunnan korkeakoulusäätiö and its collaborators, and Academy of Finland (Center of Excellence in Game Culture Studies)

\section{References}

[1] H. Abdelghaffar, and L. Samer, "Social development of rules: can social networking sites benefit e-rulemaking?", Transforming Government: People, Process and Policy 10(2), 2016, pp. 273-296.

[2] K. Al-Yafi, and M. El-Masri, "Gamification of eGovernment Services: A Potential Transformation Gamification of e-Government Services: A Discussion of Potential Transformation", Proceedings of the 22nd Americas Conference on Information Systems (AMCIS2016: Surfing the IT Innovation Wave), 2016.

[3] A. Alharbi, K. Kang, and I. Hawryszkiewycz, "The influence of trust and subjective norms on citizens' intentions to engage in e-participation on e-government websites", Australasian Conference on Information Systems(2015), 2015, pp. 1-12.

[4] C. Ampatzidou, K. Gugerell, T. Constantinescu, O. Devisch, M. Jauschneg, and M. Berger, "All Work and No Play? Facilitating Serious Games and Gamified Applications in Participatory Urban Planning and Governance", Urban Planning 3(1), 2018, pp. 34-46.

[5] K. Apostolopoulos, M. Geli, P. Petrelli, C. Potsiou, and C. Ioannidis, "A new model for cadastral surveying using crowdsourcing", Survey Review 50(359), 2018, pp. 122133.

[6] S.R. Arnstein, "A ladder of citizen participation", Journal of the American Institute of planners 35(4), 1969, pp. 216-224.

[7] A. Asquer, "Not Just Videogames: Gamification and its 
Potential Application to Public Services. Digital Public Administration and E-Government", In Professor Edward F Halpin, ed., Developing Nations: Policy and Practice. IGI Global, 2014.

[8] D. Bianchini, D. Fogli, and D. Ragazzi, "TAB sharing: A gamified tool for e-participation", Proceedings of the International Working Conference on Advanced Visual Interfaces - AVI '16, ACM Press, 2016, pp. 294-295.

[9] D. Bianchini, D. Fogli, and D. Ragazzi, "Promoting Citizen Participation through Gamification", Proceedings of the 9th Nordic Conference on Human-Computer Interaction - NordiCHI '16, ACM Press, 2016, pp. 1-4.

[10] L.B. Bingham, T. Nabatchi, and R. O'Leary, "The new governance: Practices and processes for stakeholder and citizen participation in the work of government", Public administration review 65(5), 2005, pp. 547-558.

[11] S.K. Bista, S. Nepal, C. Paris, and N. Colineau, "Gamification for online communities: A case study for delivering government services", International Journal of Cooperative Information Systems 23(2), 2014.

[12] O.Blazhko, T. Luhova, S. Melnik, and V. Ruvinska, "Communication model of open government data gamification based on Ukrainian websites", 4th Experiment@International Conference (exp.at'17), IEEE, 2017, pp. 181-186.

[13] A. Bousios, D. Gavalas, and L. Lambrinos, "CityCare: Crowdsourcing daily life issue reports in smart cities", Proceedings of the IEEE Symposium on Computers and Communications, IEEE, 2017, pp.266-271.

[14] L. Cernuzzi , and J. Pane, "Toward Open Government in Paraguay", IT Professional 16(5), 2014, pp. 62-64.

[15] P.J. Conge, "The Concept of Political Participation: Toward a Definition", Comparative Politics 20(2), 1988, pp. 241.

[16] J.E. Coronado Escobar, and A.R. Vasquez Urriago, "Gamification: an effective mechanism to promote civic engagement and generate trust?", Proceedings of the 8th International Conference on Theory and Practice of Electronic Governance - ICEGOV '14, ACM Press, 2014, pp.514-515.

[17] D.N. Crowley, J.G. Breslin, and P. Corcoran, "Gamification of Citizen Sensing through Mobile Social Reporting", proceedings of the 2012 IEEE International Games Innovation Conference (IGIC), IEEE, 2012, pp.1-5. [18] R. De , D. Bulos, D. La, J. Paolo, and R. Rivera, "Exploring Data Mining and Gamification as Tools for Poverty Analysis and Policy Formulation: A Methodological Framework.", Journal of Economic and Economic Education Research 15(3), 2014, pp. 25-37.

[19] S. Deterding, D. Dixon, R. Khaled, and L. Nacke, "From game design elements to gamefulness: defining gamification", Proceedings of the 15th International Academic MindTrek Conference on Envisioning Future Media Environments - MindTrek'11, ACM, 2011, pp. 9.

[20] O. Devisch, A. Poplin, and S. Sofronie, "The Gamification of Civic Participation: Two Experiments in Improving the Skills of Citizens to Reflect Collectively on Spatial Issues", Journal of Urban Technology 23(2), 2016, pp. 81-102.

[21] T. Eränpalo, "Exploring Young People's Civic Identities through Gamification: a case study of Finnish,
Swedish and Norwegian adolescents playing a social simulation game", Citizenship, Social and Economics Education 13(2), 2014, pp. 104-120.

[22] F.T. Fernandes, and P.T.A. Junior, "Gamification Aspects in the Context of Electronic Government and Education: A Case Study", 3rd International Conference on HCI in Business, Government, and Organizations, HCIBGO 2016, Springer, Cham, 2016, pp. 140-150.

[23] M. Foxman, and M. Forelle, "Electing to Play: MTV's Fantasy Election and Changes in Political Engagement Through Gameplay", Games and Culture 9(6), 2014, pp. 454-467.

[24] M. Gnat, K. Leszek, and R. Olszewski, "The Use of Geoinformation Technology, Augmented Reality and Gamification in the Urban Modeling Process", International Conference on Computational Science and Its Applications, Springer, Cham, 2016, pp. 484-496.

[25] M. Gurstein, "Effective Use: A Community Informatics Strategy beyond the Digital Divide", First Monday 8(12), 2003.

[26] S. Haleva-Amir, "Not all about that Facebook: political campaigns and civic engagement in the 2015 elections", Israel Affairs 22(3-4), 2016, pp. 711-726.

[27] J. Hamari, J. Koivisto, and H. Sarsa, "Does gamification work?--a literature review of empirical studies on gamification", Proceedings of the 47th Hawaii International Conference onSystem Sciences (HICSS), IEEE, 2014, pp. 3025-3034.

[28] L. Hassan, "Governments Should Play Games: Towards a Framework for the Gamification of Civic Engagement Platforms", Simulation and Gaming 48(2), 2017, pp. 249-267.

[29] L. Hassan, and A. Nader, "Gamification design in action: the practical cases of gamification platforms for employee work motivation and citizens' civic engagement", Proceedings of the International Conference on ICT Management for Global Competitiveness and Economic Growthin Emerging Economies (ICTM 2016), 2016, pp.67-70.

[30] L. Hassan, B. Morschheuser, N. Alexan, and J. Hamari, "First-hand experience of why gamification projects fail and what to do about it", Proceedings of the 2nd International GamiFIN Conference (GamiFIN2018), 2018, pp.141-150.

[31] S.-C. Hu , and I.-C. Chen, "A Gamified Online Forum Inspiring Group Intelligence Distillation for Policy Making", International Conference in Swarm Intelligence, Springer, Cham, 2015, pp.423-430.

[32] K. Huotari, and J. Hamari, "A definition for gamification: anchoring gamification in the service marketing literature", Electronic Markets 27(1), 2017, pp. 21-31.

[33] M.S. Islam, "Towards a sustainable e-Participation implementation model", European Journal of ePractice, 2008, pp. 1-12.

[34] R. Kazhamiakin, A. Marconi, A. Martinelli, M. Pistore, G.V. Fondazione, and B. Kessler-Trento, "A Gamification Framework for the Long-term Engagement of Smart Citizens", Proceedings of the IEEE 2nd International Smart Cities Conference: Improving the Citizens Quality of Life, ISC2 2016, IEEE, 2016, pp. 1-7. 
[35] R. Kazhamiakin, A. Marconi, M. Perillo, et al., "Using Gamification to Incentivize Sustainable Urban Mobility", Proceedings of 2015 IEEE First International Smart Cities Conference (ISC2), IEEE, 2015, pp. 1-6.

[36] K. Klamert, and S. Münster, "Child's Play - A Literature-Based Survey on Gamified Tools and Methods for Fostering Public Participation in Urban Planning", International Conference on Electronic Participation ePart 2017, Springer, Cham, 2017, pp. 24-33.

[37] J. Koivisto, and J. Hamari, The Rise of Motivational Information Systems: A Review of Gamification Research, 2017.

[38] S. Kumar Bista, S. Nepal, N. Colineau, and C. Paris, "Using Gamification in an Online Community", 8th International Conference on Collaborative Computing: Networking, Applications and Worksharing (CollaborateCom), IEEE, 2012, pp. 611-618.

[39] J. Lindley, and P. Coulton, "Game of Drones", Proceedings of the 2015 Annual Symposium on ComputerHuman Interaction in Play - CHI PLAY '15, ACM Press, 2015, pp.613-618.

[40] A. Macintosh, "Characterizing E-Participation in Policy-Making", Proceedings of the 37th Hawaii International Conference on System Sciences (HICSS-37), IEEE, 2004, pp.50117a (1-10).

[41] N. Mahnic, "Gamification of politics: start a new game!", Teorija in praksa 51(1), 2014, pp. 143.

[42] I.G. Martí, L.E. Rodríguez, M. Benedito, et al., "Mobile Application for Noise Pollution Monitoring through Gamification Techniques", 11th International Conference on Entertainment Computing, ICEC 2012, 2012, pp.562-571.

[43] I.S. Mayer, "The gaming of policy and the politics of gaming: A review”, Simulation and Gaming 40(6), 2009, pp. 825-862.

[44] B. Morschheuser, J. Hamari, J. Koivisto, and A. Maedche, "Gamified crowdsourcing: Conceptualization, literature review, and future agenda", International Journal of Human-Computer Studies 106, 2017, pp. 26-43.

[45] B. Morschheuser, L. Hassan, K. Werder, and J. Hamari, "How to design gamification? A method for engineering gamified software", Information and Software Technology 95, 2018, pp. 219-237.

[46] B. Morschheuser, A. Maedche, and D. Walter, "Designing Cooperative Gamification: Conceptualization and Prototypical Implementation", Proceedings of the 2017 ACM Conference on Computer Supported Cooperative Work and Social Computing - CSCW '17, 2017, pp.24102421.

[47] A. Mulyana, H. Hindersah, and A.S. Prihatmanto, "Gamification design of traffic data collection through social reporting", Proceedings of the 2015 4th International Conference on Interactive Digital Media, ICIDM 2015, IEEE, 2015, pp.1-4.

[48] S. Münster, C. Georgi, K. Heijne, et al., "How to involve inhabitants in urban design planning by using digital tools? An overview on a state of the art, key challenges and promising approaches", Procedia Computer Science 112, 2017, pp. 2391-2405.

[49] S. Nepal , C. Paris, and S. Bista, "Gamification on the Social Web", In C. Paris and D. Georgakopoulos, eds.,
Social Media for Government Services. Springer, Cham, 2015.

[50] S. Nicholson, "A User-Centered Theoretical Framework for Meaningful Gamification", Games+ Learning + Society, 2012, pp.1-7.

[51] S. Nicholson, "A RECIPE for Meaningful Gamifi cation", In Gamification in Education and Business. Springer International Publishing, 2015, pp.1-20.

[52] J. Oceja, and N.G. Fernández, "Classification of Game Experiences to Promote Civic Competence in the Context of Informal Learning", Proceedings of the 11th European Conference on Game-Based Learning, Academic Conferences International Limited, 2017, pp.480-487.

[53] R. Olszewski, A. Turek, and M. Lączyński, "Urban Gamification as a Source of Information for Spatial Data Analysis and Predictive Participatory Modelling of a City's Development", 5th International Conference on Data Management Technologies and Applications. SCITEPRESS, 2016.

[54] A. Opromolla, "'Gamified' Social Dynamics in the Interactive Systems as a Possible Solution for Increasing Co-Design of Emerging Services in Smart Territories", Proceedings of the 11th International Conference of the Italian SIGCHI Chapter, CEUR workshop proceedings, 2015, pp.46-57.

[55] A. Opromolla, A. Ingrosso, V. Volpi, C.M. Medaglia, M. Palatucci, and M. Pazzola, "Gamification in a Smart City Context. An Analysis and a Proposal for Its Application in Co-design Processes", International Conference on Games and Learning Alliance, Springer, Cham, 2015, pp.73-82.

[56] A. Opromolla, V. Volpi, and C.M. Medaglia, "Playful Interactions for the Citizens' Engagement. The Musical Language as a Possible Application", Proceedings of the International Conference on Human-Computer Interaction, Springer, Cham, 2016, pp.71-76.

[57] C. Pang, R. Pan, S. Wong, C. Neustaedter, and Y. Wu, "City Explorer: Gamifying Public Transit Trips While Exploring the City.", Proceedings of the 2017 CHI Conference Extended Abstracts on Human Factors in Computing Systems - CHI EA '17, ACM Press, 2017, pp.2825-2832.

[58] G. Paré, M.-C. Trudel, M. Jaana, and S. Kitsiou, "Synthesizing information systems knowledge: A typology of literature reviews", Information \& Management 52(2), 2015, pp. 183-199.

[59] C. Paris, and S. Nepal, "Next Step: An Online Community for Delivering Human Services", Social Media for Government Services, Springer, Cham, 2015, pp.169196.

[60] C.W. Phang, and A. Kankanhalli, "A framework of ICT exploitation for e-participation initiatives", Communications of the ACM 51(12), 2008, pp. 128.

[61] S. Poslad, A. Ma, Z. Wang, and H. Mei, "Using a Smart City IoT to Incentivise and Target Shifts in Mobility Behaviour-Is It a Piece of Pie?", Sensors 15(6), 2015, pp. 13069-13096.

[62] C. Prandi, M. Roccetti, P. Salomoni, V. Nisi, N.J. Nunes, and M. Tools Appl, "Fighting exclusion: a multimedia mobile app with zombies and maps as a medium for civic engagement and design", Multimedia 
Tools and Applications 76(4), 2017, pp. 4951-4979.

[63] N.A. Rakhmawati, and B. Fibrianto, "Designing a gamification for monitoring Surabaya City development", 2016 International Conference on Information \& Communication Technology and Systems (ICTS), IEEE, 2016, pp. 262-265.

[64] S. Rehm, "DoGood: A gamified mobile app to promote civic engagement", 2015.

[65] C.S. Rigby, "Gamification and Motivation 4", In S.P. Walz and S. Deterding, eds., The Gameful World: Approaches, Issues, Applications. MIT Press, Cambridge, MA, USA, 2015, pp. 113.

[66] M. Romano, P. Díaz, and I. Aedo, "Emergency Management and Smart Cities: Civic Engagement Through Gamification", International Conference on Information Systems for Crisis Response and Management in Mediterranean Countries, Springer, Cham, 2016, pp. 3-14. [67] A.S. Rui, D.A. Plewe, and C. Röcker, "Themed passenger carriages: promoting commuters' happiness on rapid transit systems through ambient and aesthetic intelligence.", Procedia Manufacturing 3, 2015, pp. 2103 2109.

[68] R. Sandoval-Almazan, and D. Valle-Cruz, "Open Innovation, Living Labs and Public Officials", Proceedings of the 10th International Conference on Theory and Practice of Electronic Governance - ICEGOV '17, ACM Press, 2017, pp.260-265.

[69] A.C. dos Santos, A.L. Zambalde, R.B. Veroneze, G.A. Botelho, and P.H. de Souza Bermejo, "Open Innovation and Social Participation: A Case Study in Public Security in Brazil", International conference on electronic government and the information systems perspective, Springer, Cham, 2015, pp.163-176.

[70] I. Semanjski, A. Lopez Aguirre, J. De Mol, and S. Gautama, "Policy 2.0 Platform for Mobile Sensing and Incentivized Targeted Shifts in Mobility Behavior", Sensors 16(7), 2016, pp. 1035.

[71] K. Supendi, and A.S. Prihatmanto, "Design and implementation of the assesment of publik officers web base with gamification method", Proceedings of the 2015 4th International Conference on Interactive Digital Media, ICIDM 2015, IEEE, 2015, pp. 1-6.

[72] I. Supriadi, and A.S. Prihatmanto, "Design and implementation of Indonesia united portal using crowdsourcing approach for supporting conservation and monitoring of endangered species", 2015 4th International Conference on Interactive Digital Media (ICIDM), IEEE, 2015, pp.1-6.

[73] S.-K. Thiel, "Gamified participation: investigating the influence of game elements in civic engagement tools", In Adjunct Proceedings of the 2015 ACM International Joint Conference on Pervasive and Ubiquitous Computing and Proceedings of the 2015 ACM International Symposium on Wearable Computers, ACM Press, 2015, pp.527-532.

[74] S.-K. Thiel, "Gamers in public participation: a boon or bane? influence of attitudes in gamified participation platforms", Proceedings of the 15th International Conference on Mobile and Ubiquitous Multimedia - MUM '16, ACM Press, 2016, pp.229-240.

[75] S.-K. Thiel, and P. Fröhlich, "Gamification as motivation to engage in location-based public participation?", Progress in Location-Based Services 2016 , Springer, Cham, 2017, pp.399-421.

[76] S.-K. Thiel, and U. Lehner, "Exploring the effects of game elements in m-participation", Proceedings of the 2015 British HCI Conference, ACM, 2015, pp.65-73.

[77] S.-K. Thiel, M. Reisinger, and K. Röderer, "I'm too old for this!: influence of age on perception of gamified public participation", Proceedings of the 15th International Conference on Mobile and Ubiquitous Multimedia - MUM '16, ACM Press, 2016, pp.343-346.

[78] S.-K. Thiel, and Sarah-Kristin, "Reward-based vs. Social Gamification: Exploring Effectiveness of Gamefulness in Public Participation", Proceedings of the 9th Nordic Conference on Human-Computer Interaction NordiCHI '16, ACM Press, 2016, pp.104.

[79] S.-K. Thiel, "A review of introducing game elements to e-participation", Proceedings of the 6th International Conference for E-Democracy and Open Government, CeDEM 2016, IEEE, 2016, pp.3-9.

[80] P. Tolmie, A. Chamberlain, and S. Benford, "Designing for reportability: sustainable gamification, public engagement, and promoting environmental debate", Personal and Ubiquitous Computing 18(7), 2014, pp. 1763-1774.

[81] A. Vanolo, "Cities and the politics of gamification", Cities 74, 2018, pp. 320-326.

[82] S. Virkar, "The Games People Play: Exploring Digital Addiction within the Context of the Gamification of ICT Project Design for Public Sector Administration Reform", In I.M. Association, ed., Gaming and Technology Addiction: Breakthroughs in Research and Practice. Hershey, PA: IGI Global, 2017, pp.166-194.

[83] M. Vogiatzi, C. Keratidis, M. Schinas, et al., "The STEP Project: Societal and Political Engagement of Young People in Environmental Issues", International Conference on Internet Science, Springer, Cham, 2017, pp.148-156.

[84] H. Warmelink, J. Koivisto, I. Mayer, M. Vesa, and J. Hamari, "Gamification of the work floor: A literature review of gamifying production and logistics operations", Proceedings of the 51th Annual Hawaii International Conference on System Sciences (HICSS), 2018.

[85] J. Webster, and R. Watson, "Analyzing the past to prepare for the future: Writing a literature review", $M I S$ quarterly 26(2), 2002, pp. xiii-xxiii.

[86] N.T. Weerawarna , L. Abeysiri, and A. Madhushan, "'GAIMS' - Gamified aid information management system to connect donor and requester", 2017 6th National Conference on Technology and Management (NCTM), IEEE, 2017, pp.105-110.

[87] L.K. Wei, and T. Anwar, "Analysis of motivation approach in mobile crowdsensing application: Specialize on public transportation domain", 2017 6th ICT International Student Project Conference (ICT-ISPC), IEEE, 2017, pp.1-4.

[88] B. Williamson, "Decoding ClassDojo: psycho-policy, social-emotional learning and persuasive educational technologies", Learning, Media and Technology 42(4), 2017, pp. 440-453. 